\title{
MORFOLOGÍA DE FRUTOS E SEMENTES DE PORTA-ENXERTOS DE CITROS CULTIVADOS EM AMBIENTE PROTEGIDO
}

\section{MORPHOLOGY OF FRUITS AND SEEDS OF CITRUS ROOTSTOCKS GROWN IN GREENHOUSE CONDITION}

\author{
Andrés Iván Prato Sarmiento ${ }^{1}$, Julio Cesar Giuliani ${ }^{2}$, Paulo Vítor Dutra de Souza ${ }^{3}$
}

\begin{abstract}
${ }^{1}$ Eng. Agrônomo, M.Sc. Facultad de Ciencias Agrarias, Departamento de Agronomia. Universidad de Pamplona, km 1 Vía Bucaramanga, Campus Universitario, Pamplona, Norte de Santander, Colombia, e-mail: aipratos@unal.edu.co; ${ }^{2}$ Eng. Agrônomo, M.Sc., doutorando, Faculdade de Agronomia, Programa de Pós-graduação em Fitotecnia, Universidade Federal do Rio Grande do Sul, Av. Bento Gonçalves 7712, Porto Alegre, Rio Grande do Sul, Brasil, e-mail: juliocgiuliani@yahoo.com. br; ${ }^{3}$ Eng. Agrônomo, M.Sc., Ph.D, Professor titular - Pesquisador, Faculdade de Agronomia, Programa de Pós-graduação em Fitotecnia, Universidade Federal do Rio Grande do Sul, Av. Bento Gonçalves 7712, Rio Grande do Sul Porto Alegre, Brasil, e-mail: pvdsouza@ufrgs.br
\end{abstract}

Rev. U.D.C.A Acr. \& Div. Cient. 19(1): 17-24, Enero-Junio, 2016

\section{RESUMO}

O ambiente de cultivo pode influenciar a morfologia dos frutos, bem como tempo de germinação e viabilidade das sementes para a obtenção dos porta-enxertos cítricos. Objetivou-se determinar as características morfológicas dos frutos e o comportamento germinativo de sementes de sete cultivares porta-enxertos de citros cultivados em ambiente protegido. Foram avaliados os porta-enxertos citrangeiros 'FEPAGRO C13', 'FEPAGRO C37' e 'Troyer' (Poncirus trifoliata [L] Raf. x Citrus sinensis [L.] Osb.), a tangerineira 'Sunki' (Citrus sunki Hort. ex Tan.), o limoeiro 'Volkameriano' (Citrus volkameriana Ten. \& Pasq.), o trifoliata ( $P$. trifoliata) e o citrumeleiro 'Swingle' ( $P$. trifoliata $\mathrm{x}$ Citrus paradisi). Empregou-se o delineamento interiamente casualizado, com três repetições de treze frutos por cultivar. Mediu-se o diâmetro e comprimento e a massa por fruto. Foi calculado o número de frutos e de sementes viáveis por caixa de colheita $(25 \mathrm{~kg})$. As sementes viáveis destes frutos foram colocadas em câmara de germinação e crescimento tipo B.O.D. O citrumeleiro 'Swingle' produziu frutos maiores e com maior massa, a tangerineira 'Sunki' produziu os menores, e as demais cultivares produziram frutos com padrão intermediário às anteriores. São necessários 87,7 frutos de citrumeleiro 'Swingle' para preencher uma caixa de colheita e mais de 1.051,7 frutos de tangerineira 'Sunki' para o mesmo volume. As sementes de tangerineira 'Sunki' e do limoeiro 'Volkameriano' apresentaram maior velocidade de germinação em relação aos outros porta-enxertos, com 75\% de germinação aos 30 dias após a semeadura. Matrizes de porta-enxertos de citros cultivados em ambiente protegido produzem sementes viáveis e poder germinativo próximo a $80 \%$.

Palavras chave: Sistema de propagação, germinação, citricultura, casa de vegetação.

\section{SUMMARY}

The environment the crop can influence the morphology of the fruit, as well as the time of germination and the viability of the seeds, for obtaining the citrus rootstocks. The objetive of this work was to determine the morphological characteristics of the fruits, and the germination performance of the seeds of seven cultivars of citrus rootstocks cultivated in a greenhouse. The rootstocks evaluated were: citranger 'FEPAGRO C13', 'FEPAGRO C37' and 'Troyer' (Poncirus trifoliata [L.] Raf. $\mathrm{x}$ Citrus sinensis [L.] Osb.), 'Sunki' mandarin (Citrus sunki Hort. ex Tan.), lemon 'Volkamer' (Citrus volkameriana Ten. \& Pasq.), trifoliate ( $P$. trifoliata) and citrumelo 'Swingle' $(P$. trifoliata $\mathrm{x}$ Citrus paradisi). A completely randomized design was used, with tree repetitions of 13 fruits per cultivar. Fruit diameter, length and mass were measured. Number of viable seeds and fruits by harvest box $(25 \mathrm{~kg})$ was calculated. The viable seeds of these fruits were put in a germination and a growth B.O.D type chamber. The citrumelo 'Swingle' produced larger and heavier fruit, while the tangerine 'Sunki' produced the smallest fruit, and the other cultivars produced fruits with a pattern between the two. It takes 87,7 of citrumelo fruit 'Swingle' to fill a harvest box and more than 1.051,7 of 
tangerine fruit 'Sunki' to fill the same volume. The mandarin seeds 'Sunki' and lemon seeds 'Volkamer' showed a higher germination speed compared to other rootstocks, with a 75\% of germination after 30 days of the sowing. Mother plants of citrus rootstocks grown in greenhouses produce viable seeds with a high germination power, close to $80 \%$.

Key words: Propagation system, germination, citriculture, greenhouse.

\section{INTRODUÇÃO}

Na produção de mudas cítricas de qualidade, há que se atentar para aspectos fundamentais ligados à sua garantia genética, aos métodos de propagação, aos sistemas de produção e à legislação vigente (Koller, 2009). Neste processo é necessário que os porta-enxertos apresentem condições ótimas em quanto a seu desenvolvimento vegetativo e formação do sistema radicular. Com tudo, os porta-enxertos podem afetar mais de 20 características hortícolas da cultivar copa (Schäfer et al. 2001).

A diversificação varietal dos porta-enxertos constitui uma premissa à citricultura brasileira, visando reduzir a susceptibilidade ao ataque de pragas e ocorrência de estresses abióticos. Uma ampliação da base genética das cultivares usadas para porta-enxertos contribuirá para aumentar os rendimentos e a sustentabilidade do setor. No entanto, não é o que tem ocorrido historicamente na citricultura brasileira, caracterizada pelo uso preponderante de uma cultivar, por exemplo, o limoeiro 'Cravo' (Citrus limonia Osb.) no estado de São Paulo (Pompeu Junior \& Blumer, 2011). No final do século passado mais de $90 \%$ da citricultura gaúcha era enxertada sobre o trifoliata (Poncirus trifoliata [L.] Raf.) (Schäfer \& Dornelles, 2000).

A grande aceitação do trifoliata e seus híbridos no sul do Brasil deve-se ao fato de apresentar tolerância ao frio, aos solos rasos, às geadas e à gomose (Phytophthora spp.), além de induzir a produção de frutos de ótima qualidade das copas (Souza et al. 2010). Tem-se testado outros portaenxertos com intuito de verificar quais características eles podem conferir para a cultivar - copa. Entre eles estão os citrangeiros 'FEPAGRO C13' e 'FEPAGRO C37' ( $P$. trifoliata $\mathrm{x}$ Citrus sinensis [L.] Osb.), desenvolvidos pela Fundação Estadual de Pesquisa Agropecuária (Taquari, RS); o citrumeleiro 'Swingle' (P. trifoliata x Citrus paradisi Macfad. cv. Duncan); a tangerineira 'Sunki' (Citrus sunki Hort. ex Tan.) e o limoeiro 'Cravo' (Souza et al. 2010).

Existe a preocupação de produzir-se borbulhas em ambiente protegido, visando um programa de certificação, pois permite melhoria na qualidade genética e sanitária das borbulhas utilizadas na formação das mudas (Carvalho et al. 2000). Esta preocupação é cabível, também, com as plantas matrizes produtoras de sementes de porta-enxertos, principalmente sob o aspecto sanitário. Porém, há dúvidas quanto à quantidade e à viabilidade de sementes produzidas em frutos de plantas cítricas cultivadas em ambiente protegido, visto que não há insetos polinizadores no interior das casas de vegetação. Os porta-enxertos e, em geral, as plantas cítricas mostram-se preferencialmente autógamas ou alógamas segundo a cultivar (Nascimento et al. 2011; Pok et al. 2015).

Dentre as fases de desenvolvimento da muda cítrica, a produção do porta-enxerto é responsável por uma maior demanda de tempo. Um dos fatores responsáveis por essa demora é o tempo de germinação (Siqueira et al. 2002), em consequência, pode existir desuniformidade no desenvolvimento entre as plântulas (Sousa et al. 2002). O conhecimento desta fase, que é variável por cultivar, é importante para a definição de todo o período necessário para produzir a muda.

A citricultura brasileira exige anualmente uma enorme quantidade de mudas, sendo sua planificação um fator determinante para o sucesso do setor. Por tanto, a estimação da quantidade necessária do número de frutos que devem ser colhidas para obtenção de certa quantidade de sementes, facilita a produção e beneficia aos viveiristas e produtores (Zucoloto et al. 2011).

Atualmente, existe uma demanda crescente por mudas cítricas de cultivares de mesa para o Rio Grande do Sul. A legislação vigente exige que as mudas sejam produzidas em ambiente protegido, aumentando a importância de pesquisas com porta-enxertos, por haver carência de informações para esta tecnologia neste Estado. Este trabalho teve como objetivos estudar a influência do ambiente protegido sobre as características morfológicas dos frutos e a viabilidade das sementes produzidas por sete cultivares de porta-enxertos de citros.

\section{MATERIAL E MÉTODOS}

As plantas matrizes das quais foram retirados os frutos encontram-se em casa de vegetação da Estação Experimental Agronômica da Universidade Federal do Rio Grande do Sul,

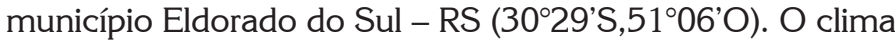
da região, baseado na classificação de Köppen, é do tipo Cfa, ou seja, subtropical úmido. Atualmente as plantas enxertadas sobre trifoliata têm dez anos de idade, sendo mantidas em vasos (100L), contendo substrato à base de solo, resíduo de casca de acácia e casca de arroz carbonizada (2:2:1 v:v:v). O sistema de irrigação é por gotejamento, sendo irrigadas diariamente e fertilizadas quinzenalmente mediante fertirrigação). $\mathrm{O}$ adubo consiste em $5 \mathrm{~g}$ de Kristalon ${ }^{\circledR}(6 \%$ 
nitrogênio total, sendo 4,5\% $\mathrm{N}$ - nítrico e 1,5\% $\mathrm{N}$-amoniacal; $12 \%$ P, 36\% K; 8\% Mg; 8\% S; 0,07\% Fe; 0,025\% B; 0,01\% Cu; 0,04\% Mn; 0,004\% Mb; e 0,025\% de Zn) diluídos em 1,5L e distribuídos $50 \mathrm{~mL}$ por vaso.

Inicialmente realizou-se a avaliação morfológica dos frutos produzidos pelas seguintes cultivares de porta-enxertos de citros: os citrangeiros 'FEPAGRO C13', 'FEPAGRO C37' e 'Troyer' (P. trifoliata x C. sinensis), a tangerineira 'Sunki' (C. sunki), o limoeiro 'Volkameriano' (Citrus volkameriana Ten. \& Pasq.), o trifoliata (P. trifoliata) e o citrumeleiro 'Swingle' (P. trifoliata x C. paradisi). Foram coletados aleatoriamente, 39 frutos maduros e sadios por cultivar, a partir de três plantas em cada uma, os quais foram levados ao laboratório, sendo realizadas as seguintes avaliações: diâmetro $(\mathrm{mm})$ e comprimento $(\mathrm{mm})$ dos frutos, com auxílio de paquímetro, e a massa por fruto $(\mathrm{g})$ por meio de balança analítica. Também foi calculado o número de frutos por caixa de colheita (NFC), levando-se em consideração as dimensões de $55 \times 35 \times 15 \mathrm{~cm}$ (comprimento $\mathrm{x}$ largura $\mathrm{x}$ altura, respectivamente) (Zucoloto et al. 2011):

$$
\mathrm{NFC}=\frac{55(\mathrm{~cm})}{\text { diâmetro }} \times \frac{35 \mathrm{~cm}}{\text { médiômetro }} \times \frac{15 \mathrm{~cm}}{\text { comprimento }} \times \frac{\text { frutos }(\mathrm{cm})}{\text { médio dos frutos }(\mathrm{cm})}
$$

A seguir, as sementes foram extraídas e lavadas com agua corrente para a retirada da mucilagem, segundo metodologia descrita por Koller (1994). A secagem foi feita à sombra. Após sua extração, contou-se o número de sementes viáveis e inviáveis por fruto. Foram consideradas sementes viáveis aquelas cheias, com presença de material de reserva e embrião; e como inviáveis, as vazias ou não desenvolvidas, sem embrião no seu interior ou com embrião morto. As sementes viáveis foram tratadas termicamente $\left(52^{\circ} \mathrm{C}, 10 \mathrm{~min}\right.$.) e com fungicida Captam ${ }^{\circledR}$ 500PM (pó solúvel, i.a: N-triclorometiltio-4-ciclohexeno-1,2dicarboximida, $500 \mathrm{~g}$ de i.a/ $\mathrm{kg}$ ), permanecendo em geladeira $\left(4\right.$ a $\left.6^{\circ} \mathrm{C}\right)$ dentro de sacos de polietileno por 18 dias até a semeadura. As sementes viáveis foram distribuídas, sem a retirada do tegumento, em caixas tipo Gerbox ${ }^{\circledR}$ com dimensões $11 \times 3,5 \mathrm{~cm}$ - largura x profundidade, forradas com papel germitest umedecido até sua máxima absorção e colocadas em câmara de crescimento e germinação tipo B.O.D ('Biological Oxygen Demand' - modelo FOC 225E). Permaneceram a $24^{\circ} \mathrm{C}$ sem a utilização de luz e irrigadas com água destilada regularmente.

Para as avaliações de diâmetro dos frutos, número de fruto por caixa e número de sementes viáveis por fruto empregou-se o delineamento experimental inteiramente casualizado, com sete tratamentos (cultivares de portaenxertos) e três repetições de 13 frutos por cultivar. Os dados foram submetidos à análise de variância e as médias foram comparadas pelo teste Tukey, a 5\% de probabilidade, com o programa estatístico SAS 9.3 ®.

O índice de velocidade de germinação (IVG) foi calculado a traves da fórmula proposta por Maguire (1962): IVG $=\mathrm{G}_{1} /$ $\mathrm{N}_{1}+\mathrm{G}_{2} / \mathrm{N}_{2}+\ldots+\mathrm{Gn} / \mathrm{N}\left(\mathrm{G}_{1}, \mathrm{G}_{2}, \mathrm{Gn}=\right.$ número de plântulas germinadas na primeira, segunda, até a última contagem aos 60 dias após a semeadura, eliminando-se, periodicamente, aquelas decompostas ou contaminadas e $\mathrm{N}_{1}, \mathrm{~N}_{2}, \mathrm{Nn}=$ número de semanas desde a primeira, segunda, até a última contagem).

Para a execução desta etapa, empregou-se o delineamento inteiramente casualizado com sete tratamentos (sete cultivar porta-enxerto) com quatro repetições, sendo cada parcela representada por um Gerbox (®) contendo 25 sementes. Finalmente, com os dados periódicos de germinação foram elaboradas curvas de germinação acumulada, com ajustes por meio de regressões variadas (Santana \& Renal, 2000). Esse ajuste foi efetuado pelo programa ASSISTAT $7.6{ }^{\circledR}$, seguindo como critérios de seleção de modelo o coeficiente de determinação e a facilidade de interpretação dos dados biológicos pelas equações.

\section{RESULTADOS E DISCUSSÃO}

As caraterísticas morfológicas dos frutos foram diferentes significativamente entre os porta-enxertos, para todas as variáveis avaliadas (Tabela 1). Os frutos do citrumeleiro 'Swingle' apresentaram maior comprimento e diâmetro (72,1 mm e $67,7 \mathrm{~mm}$, respectivamente), além de ter mais massa $(155,1 \mathrm{~g})$, comparativamente aos da tangerineira 'Sunki' (Tabela 1). Os citrangeiros 'FEPAGRO C13 e C37', além do citrangeiro 'Troyer' e trifoliata apresentaram frutos de tamanho intermediários.

O citrumeleiro 'Swingle' teve o maior número total de sementes por fruto, $(51,0)$, porém com alta porcentagem de sementes inviáveis $(47,8 \%)$ (Figura 1$)$. O menor número de sementes por fruto foi encontrado no FEPAGRO 'C37' $(7,4$ sementes por fruto), com aproximadamente metade delas inviáveis. Contrariamente, o trifoliata apresentou a maioria de suas sementes viáveis $(97,0 \%)$ e alta quantidade por fruto (37,7 sementes) (Figura 1). As cultivares FEPAGRO 'C13', citrangeiro 'Troyer', limoeiro 'Volkameriano' e tangerineira 'Sunki', apresentaram, em média, 23,3; 18,1; 18,3; e 6,9; sementes viáveis por fruto, respectivamente (Figura1).

Guerra et al. (2012) encontraram números de sementes viáveis semelhantes ao do presente estudo nas cultivares cultivadas em campo citrangeiro 'Troyer', 'FEPAGRO C13', trifoliata e citrumeleiro 'Swingle' (16,6; 19,2; 38,2 e 23,3, respectivamente), porem superior em relação ao citrangeiro 'FEPAGRO C37' $(21,2)$. No caso da tangerineira 'Sunki', 
Tabela 1. Diâmetro (DF), comprimento (CF) e massa média por fruto (MF), de sete porta-enxertos de citros cultivados em ambiente protegido.

\begin{tabular}{|l|c|c|c|}
\hline \multicolumn{1}{|c|}{ Porta-enxerto } & DF (mm) & CF (mm) & MF (g) \\
\hline Citrangeiro 'Troyer' & $45,0 ~ d \mathrm{de}^{*}$ & $45,7 \mathrm{~d}$ & $49,9 \mathrm{~d}$ \\
\hline Citrumeleiro 'Swingle' & $67,7 \mathrm{a}$ & $72,1 \mathrm{a}$ & $155,1 \mathrm{a}$ \\
\hline Citrangeiro 'FEPAGRO C 37' & $50,2 \mathrm{~cd}$ & $46,6 \mathrm{c}$ & $64,6 \mathrm{c}$ \\
\hline Citrangeiro 'FEPAGRO C 13' & $48,1 \mathrm{c}$ & $47,7 \mathrm{c}$ & $56,6 \mathrm{~cd}$ \\
\hline Limoeiro 'Volkameriano' & $55,2 \mathrm{~b}$ & $63,3 \mathrm{~b}$ & $97,9 \mathrm{~b}$ \\
\hline 'Trifoliata' & $44,2 \mathrm{e}$ & $43,5 \mathrm{~d}$ & $47,2 \mathrm{~d}$ \\
\hline Tangerineira 'Sunki' & $32,7 \mathrm{f}$ & $25,8 \mathrm{e}$ & $16,1 \mathrm{e}$ \\
\hline cv \% & 22,0 & 30,1 & 64,4 \\
\hline
\end{tabular}

* Médias seguidas pela mesma letra, na coluna, não diferem entre si pelo teste de Tukey a 5\% de probabilidade de erro.

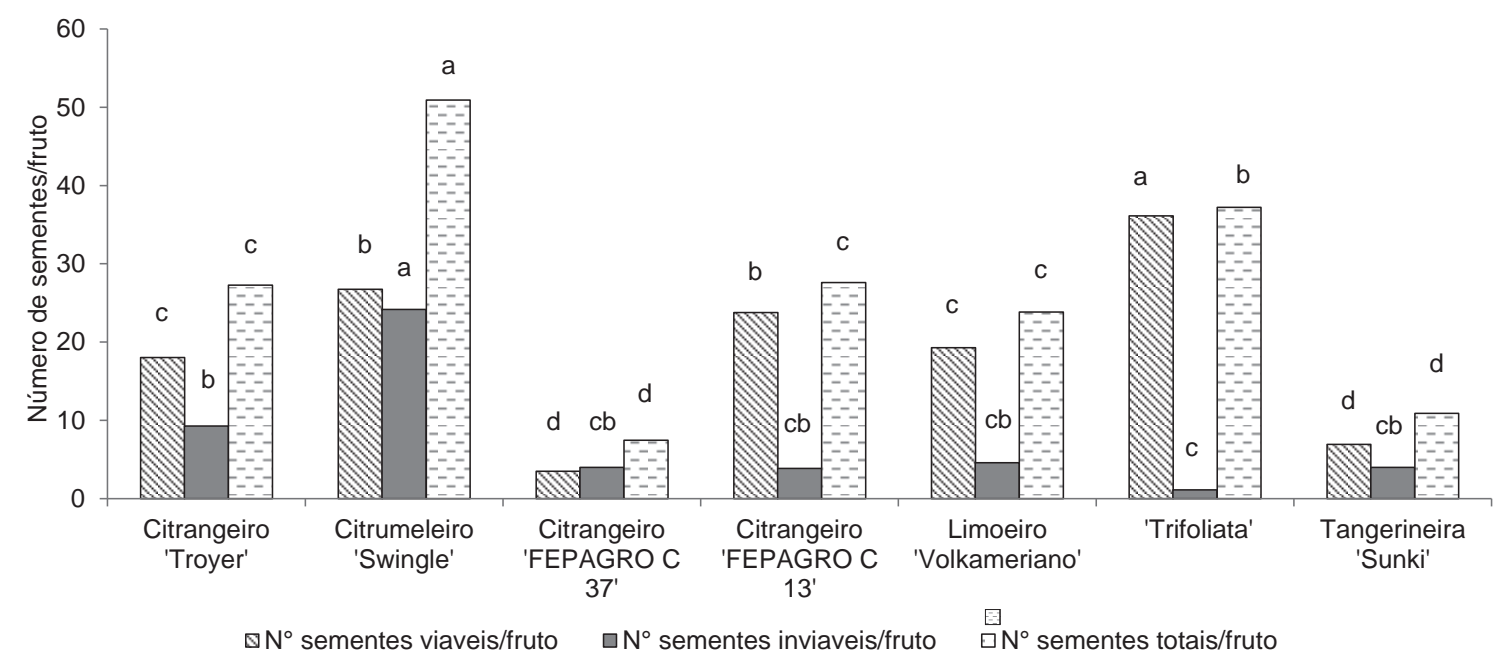

Figura 1. Número de sementes viaveis, inviaveis e total de sementes por fruto de sete porta-enxertos de citros cultivados em ambiente protegido. Médias seguidas pela mesma letra para cada parâmetro não diferem entre si pelo teste de Tukey a 5\% de probabilidade de erro.

normalmente, esta cultivar tem valores reduzidos, entre duas a três sementes viáveis por fruto (Carvalho et al. 1997; Santos et al. 2015). Carvalho et al. (1997) relataram que devido ao alto grau de auto-incompatibilidade, quando a tangerineira 'Sunki' cultivada em campo foi polinizada com espécies compatíveis, houve um aumento significativo no número de sementes por fruto, até dezessete sementes por fruto, o que explicaria o valor elevado deste estudo (10,9 sementes totais por fruto). Adicionalmente, comprovou-se que esse aumento dependeu do polinizador especifico utilizado. Contudo, do ponto de vista da obtenção de embriões nucelares para a produção de mudas, tal aumento seria prejudicial, dado que se teria maior número de plantas zigóticas a expensas das nucelares.

Além do fator genético, existem variações em características de frutos e sementes de porta-enxertos conforme a região de estudo. No México, Andrade et al. (2003) verificaram maior massa $(158,5 \mathrm{~g})$ e diâmetro $(66,2 \mathrm{~mm})$ dos frutos do limoeiro 'Volkameriano' em relação ao presente estudo. Na Venezuela, Monteverde et al. (2007), avaliando esta mesma cultivar em campo, encontraram diâmetro de fruto e número de sementes por fruto semelhantes ao presente estudo, com a massa por fruto superior $(188 \mathrm{~g})$. As possíveis variações nos 
resultados são atribuídas a fatores ambientais, principalmente temperatura (Monteverde et al. 2007), condições de cultivo e a possível diversidade de seleção da espécie (Guerra et al. 2012).

Nos citros a polinização é necessária para a formação do embrião zigótico, sendo este indispensável pelo suprimento de nutrientes e hormônios essenciais para o desenvolvimento dos embriões nucelares, e assim, a formação de sementes viáveis (Koltunow, 1993; Machado et al. 2005). As diferenças na viabilidade das sementes observadas neste estudo podem ser devidas às maiores ou menores necessidades de polinização cruzada nas cultivares (Pok et al. 2015).

Para a cultura dos citros o processo de fertilização ébeneficiado principalmente por insetos polinizadores (Nascimento et al. 2011), os quais estavam ausentes da casa de vegetação. A presença de embrióes viáveis deve ser consequência da polinização anemófila (Lim et al. 2001), pois todas as plantas eram cultivadas na mesma casa de vegetação, com cortinas laterais confeccionadas com telas antiafídicas, que permitia passagem do vento. Adicionalmente, a primavera no sul do Brasil, época de floração dos citros, caracterizase por presença constante de ventos, o que favoreceu a polinização mesmo em ambiente protegido.

Ao quantificar-se o número de frutos por caixa de $25 \mathrm{~kg}$ e de sementes por fruto verificou-se que os valores diferiram amplamente entre os porta-enxertos (Tabela 2). As diferenças em número de frutos deveram-se aos diferentes tamanhos dos mesmos. Enquanto que com somente 81,43 frutos de citrumeleiro 'Swingle' se enche uma caixa de colheita, são necessários 1.056,3 frutos de tangerineira 'Sunki' para preencher o mesmo volume. Para porta-enxertos cultivados em campo, no limoeiro 'Volkameriano', citrangeiro 'Swingle' e tangerineira 'Sunki', Zucoloto et al. (2011) encontraram necessários 149, 199 e 2.909 frutos para encher uma caixa de colheita de $28 \mathrm{~kg}(51 \times 31 \times 18 \mathrm{~cm})$. Multiplicando-se o número de frutos por caixa pelos embriões viáveis por fruto, verificou-se ampla variação por caixa de colheita segundo a cultivar. O trifoliata apresentou maiores valores, 12.844,2 sementes viáveis, superior ao citrumeleiro 'Swingle' $(825,1)$ (Tabela 2).

A exceção da tangerineira 'Sunki' que foi quadrática, os demais porta-enxertos seguiram um padrão cubico nas curvas de germinação acumulada. A tangerineira 'Sunki' e o limoeiro 'Volkameriano' apresentaram a maioria das sementes germinadas precocemente em relação aos outros porta-enxertos, com $76,5 \%$ e $74,5 \%$ de germinação aos 30 dias após a semeadura, respectivamente (Figura 2). Em comparação, os porta-enxertos citrangeiro 'FEPAGRO C13', 'Troyer', 'Swingle' e o trifoliata atingiram 68,9\%, 64,3\%, $59,9 \%$ e $72,1 \%$ em germinação 60 dias após a semeadura, respectivamente, ou seja, o fizeram em forma tardia (Figura 2). Dias et al. (2012) testando a germinação das sementes de limoeiro 'Volkameriano', tangerineira 'Sunki' e citrumeleiro 'Swingle', mantidos em germinador a $30^{\circ} \mathrm{C}$ por 45 dias encontraram resultados próximos ao do atual trabalho. Carvalho \& Silva (2013), testando estes mesmos portaenxertos, junto ao trifoliata e limoeiro 'Volkameriano', após dois meses e temperatura de $25^{\circ} \mathrm{C}$ em germinador, também descreveram resultados semelhantes a este estudo. Nestes estudos as matrizes dos porta-enxertos foram cultivadas em campo.

Tabela 2. Número de frutos (NFC), sementes viáveis por caixa (NSVC), índice de velocidade de germinação (IVG) e percentagem de germinação final (\%G) de sete porta-enxertos de citros cultivados em ambiente protegido.

\begin{tabular}{|l|c|c|c|c|}
\hline \multicolumn{1}{|c|}{ Porta-enxerto } & NFC & NSVC & IVG & $\% G$ \\
\hline Citrangeiro 'Troyer' & $312,3 \mathrm{~b}$ " & $5666,4 \mathrm{~b}$ & $1,2 \mathrm{c}$ & $71,0 \mathrm{~b}$ \\
\hline Citrumeleiro 'Swingle' & $87,7 \mathrm{e}$ & $825,1 \mathrm{~d}$ & $1,5 \mathrm{c}$ & $65,0 \mathrm{~b}$ \\
\hline Citrangeiro 'FEPAGRO C 37' & $248,9 \mathrm{c}$ & $2314,0 \mathrm{~cd}$ & $2,8 \mathrm{~b}$ & $90,0 \mathrm{a}$ \\
\hline Citrangeiro 'FEPAGRO C 13' & $248,9 \mathrm{c}$ & $6095,3 \mathrm{~b}$ & $1,7 \mathrm{c}$ & $69,0 \mathrm{~b}$ \\
\hline Limoeiro 'Volkameriano' & $150,4 \mathrm{~d}$ & $2757,0 \mathrm{c}$ & $3,8 \mathrm{a}$ & $89,7 \mathrm{a}$ \\
\hline 'Trifoliata' & $341,2 \mathrm{~b}$ & $12844,2 \mathrm{a}$ & $1,5 \mathrm{c}$ & $80,0 \mathrm{ab}$ \\
\hline Tangerineira 'Sunki' & $1051,7 \mathrm{a}$ & $7275,2 \mathrm{~b}$ & $4,4 \mathrm{a}$ & $92,0 \mathrm{a}$ \\
\hline \multicolumn{1}{|c|}{ cv \% } & 91,9 & 74,5 & 54,7 & 14,2 \\
\hline
\end{tabular}

* Médias seguidas pela mesma letra, na coluna, não diferem entre si pelo teste de Tukey a 5\% de probabilidade de erro. 


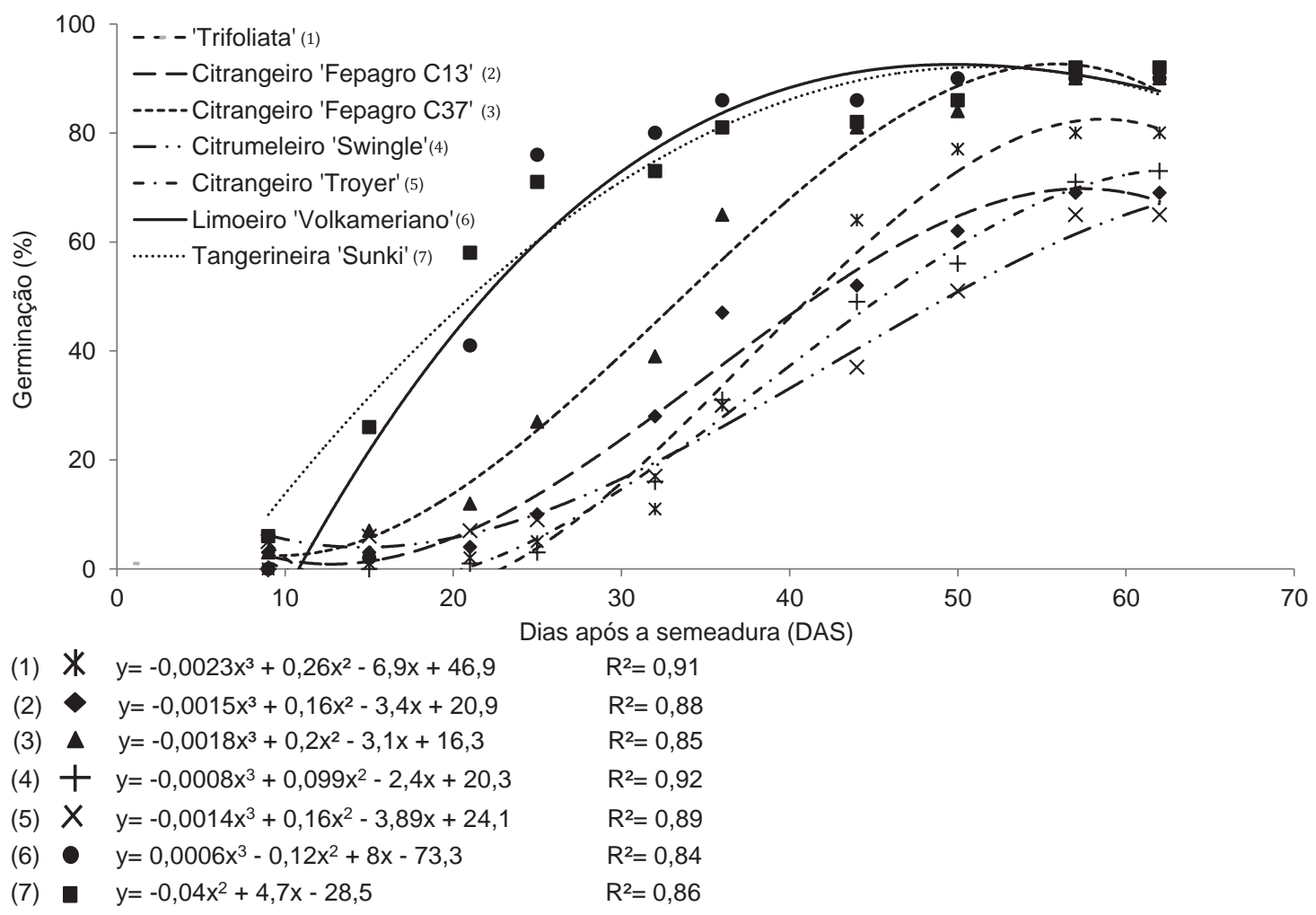

Figura 2. Curvas de germinação acumulada de sete porta-enxertos de citros cultivados em ambiente protegido.

O índice de velocidade de germinação (IVG) foi maior para tangerineira 'Sunki' $(4,2)$, seguido do limoeiro 'Volkameriano' $(3,6)$ (Tabela 2$)$, o que se corrobora com os resultados obtidos nas curvas de germinação acumulada. Os demais portaenxertos apresentaram IVGs menores, o que indica maior desuniformidade de germinação quando comparado aos anteriores. Também, IVGs menores indicam a necessidade de mais tempo para a produção de mudas ao se relacionar com o vigor das sementes, visto que os porta-enxertos levam mais tempo para atingir o ponto de enxertia.

O uso de porta-enxertos menos vigorosos requer maiores cuidados de manejo desde a sua semeadura, visando acelerar seu desenvolvimento e evitar o risco de produzir a muda além do tempo estabelecido pela legislação vigente no Brasil. Este não deve exceder os 6 meses a partir da data de semeadura, no caso do porta-enxerto e não mais do que 12 meses a partir da enxertia até a muda pronta para comércio (Azevêdo, 2003). Porém, isto não significa que não devam ser recomendados e utilizados para uso em citricultura, pois a diversificação é fundamental para reduzir riscos com algum novo problema fitossanitário que possa vir a ocorrer. Principalmente, porque todos os porta-enxertos avaliados são reconhecidamente excelentes para as condições de solo e clima do sul do Brasil (Koller, 2009; Souza et al. 2010), proporcionando excelente qualidade dos frutos produzidos pelas copas sobre eles enxertadas.

No estado do Rio Grande do Sul, de clima temperado, o tempo de produção de mudas cítricas feitas anteriormente pelo sistema tradicional era longo, ou seja, três anos (Schäfer \& Dornelles, 2000). Quando são produzidas em ambiente protegido, nota-se redução do tempo requerido, além de facilitar a produção livre de patógenos, portanto, oferecendo maiores garantias de qualidade genética e fitossanitária (Schäfer \& Dornelles, 2000; Oliveira \& Scivittaro, 2004; Scivittaro et al. 2004). Tais vantagens ressaltassem com o presente estudo, pois o cultivo em ambiente protegido parece não prejudicar a velocidade de germinação das sementes dos porta-enxertos avaliados.

A germinação pode ser limitada ou retrasada pela a presença do tegumento nas sementes, o que pode ter influenciado o índice de velocidade de germinação. Moreira et al. (2010) e Rodrigues et al. (2010) observaram maior germinação em sementes sem tegumento em porta-enxertos de citros, associado possivelmente à limitação hídrica promovida pelo tegumento. De tal maneira, alguns dos porta-enxertos avaliados neste estudo talvez necessitassem de tratamentos prévios de remoção do tegumento. Teixeira et al. (2009) 
verificaram que a escarificação química de tegumento proporcionou melhorias na velocidade de emergência e na taxa de emergência para os porta-enxertos 'FEPAGRO C37' e trifoliata.

Finamente, neste estudo conclui-se que plantas matrizes fornecedoras de sementes de porta-enxertos de citros em ambiente protegido apresentam número de sementes viáveis próximas ao cultivo em campo. Também, se conclui que em ambiente protegido, as sementes viáveis dos sete porta-enxertos avaliados apresentaram em média 79,5\% de germinação aos 60 dias após semeadura, com o citrangeiro 'Troyer' e a tangerineira 'Sunki' atingindo um mínimo e máximo de $92 \%$ e $71 \%$, respectivamente. A velocidade de germinação foi maior na tangerineira 'Sunki' e o limoeiro 'Volkameriano', e menor no citrumeleiro 'Swingle', com os citrangeiros apresentando resultados intermediários entre os anteriores.

Agradecimentos: Ao $\mathrm{CNPq}$ (Conselho Nacional de Desenvolvimento Científico e Tecnológico) e à FAPERGS (Fundação de Amparo à Pesquisa do Estado do Rio Grande do Sul) pelo apoio financeiro. Conflitos de interesses: O manuscrito foi elaborado e revisado com a participação de todos os autores, na qual declaramos que não existe nenhum conflito de interesse que coloque em risco a validez dos resultados apresentados.

\section{BIBLIOGRAFIA}

1. ANDRADE, M.A.; VILLEGAS, A.; GARCÍA, A. 2003. Características morfológicas del fruto y poliembrionía de tres portainjertos de cítricos. Rev. Chapingo Serie Horticultura (México). 9(2):255-263.

2. AZEVÊDO, C.L. 2003. Produção Integrada de Citros-BA. Sistemas de Produção, 15. EMBRAPA - EMPRAPA Mandioca e Fruticultura. Disponible desde internet en: http://sistemasdeproducao.cnptia.em brapa.br/ FontesHTML/Citros/CitrosBahia_2ed/sementes.htm.

3. CARVALHO, S.A.; SILVA, J.A.; SEMPIONATO, O.R. 2000. Produção de borbulhas certificadas de citros no Estado de São Paulo. Ed. FUNEP (Jaboticabal). 26p.

4. CARVALHO, S.A.; SILVA, L.F. 2013. Monitoring the viability of citrus rootstocks seeds stored under refrigeration. Rev. Bras. Fruticult. 35(1):238-245.

5. CARVALHO, M.R.; BORDIGNON, R.; BALLVÉ, R.M.; MAGLIO, R.M.; MEDINA, H. 1997. Aspectos biológicos do reduzido número de sementes da tangerina Sunki'. Bragantia (Brasil). 56(1):69-77.
6. DIAS, M.; ZUCOLOTO, M.; DIAS, D.C.; SILVA, D.F.; SEDIYAMA, C.A.; NETO, J. 2012. Resposta fisiológica de sementes de variedades portaenxertos de citros submetidas à condicionamento osmótico. Comunicata Scientiae (Brasil). 3(4):238-243.

7. GUERRA, D.; WITTMAN, M.T.S.; SCHWARZ, S.F.; SOUZA, P.V.D.; WEILER, R.L. 2012. Caracterização morfológica, determinação do número de embriões e taxa de poliembrionia em três porta-enxertos híbridos de citros. Bragantia. 71(2):196-201.

8. KOLLER, O.C. 1994. Citricultura: laranja, limão e tangerina. Ed. Rígel (Porto Alegre). 446 p.

9. KOLLER, O.C. 2009. Citricultura: Cultura de Tangerineiras: tecnologia de produção, pós-colheita e industrialização. Ed. Rígel. 400p.

10. KOLTUNOW, A.M. 1993. Apomixis: Embryo sacs and embryos formed without meiosis or fertilization in ovules. The Plant Cell (USA). 5(10):1425-1437.

11. LIM, A.L. 2001. Citrus and citroids: Recent biological findings. Malayan-Nature Journal. 55:221-229. 2001.

12. MACHADO, M.A.; CRISTOFANI, M.; AMARAL, A.M.; OLIVEIRA, A.C. 2005. Genética, melhoramento e biotecnologia de citros. En: MATTOS JÚNIOR, D.; DE NEGRE, J.D.; PIO, R.M.; POMPEU JUNIOR, J. (Eds.). Citros. Ed. FUNDAG (Jaboticabal). p.221277.

13. MAGUIRE, J.D. 1962. Speed of germination-aid in selection and evaluation for seedling emergence and vigor. Crop Science (USA). 2(1):176-177.

14. MONTEVERDE, E.E.; MARIN, R.; RUIZ, J.R. 2007. Estudio de algunas características del fruto de ocho portainjertos para cítricos. Agr. Trop. (Venezuela). 57(3):189-195.

15. MOREIRA, R.A.; RAMOS, J.D.; CRUZ, M.M. 2010. Caracterização de frutos e poliembrionia em sementes de 'Flying Dragon' e de híbridos de portaenxerto de citros. Rev. Bras. Fruticult. 32(2):486-492.

16. NASCIMENTO, E.T.; MALUF, R.P.; GUIMARÃES, R.A.; CASTELLANI, M.A. 2011. Diversidade de abelhas visitantes das flores de Citrus em pomares de laranjeira e tangerineira. Rev. Bras. Fruticult. 33(1):111-117. 
17. OLIVEIRA, R.P.; SCIVITTARO, W.B. 2004. Infraestrutura e custo de produção de mudas de citros (Documentos, 118). Embrapa Clima Temperado. (Pelotas). 27p.

18. POK, P.; OH, E.U.; YI, K.; KANG, J.H.; KO, B.J.; KIM, H.B.; SON, K.J. 2015. Characterization of microspore development and pollen tube growth response to self- and cross-pollination in Jeju old local citrus species. Hort. Environ. Biotechnol. 56(2):225-232.

19. POMPEU JUNIOR, J.; BLUMER, S. 2011. Citrandarins e outros híbridos de trifoliata como porta-enxerto para laranjeira Valencia. Citrus Res. Technol. (Brasil). 32(3): 133-138.

20. RODRIGUES, F.; FREITAS, G.; MOREIRA, R.; PASQUAL, M. 2010. Caracterização dos frutos e germinação de sementes dos porta-enxertos Trifoliata Flying Dragon e citrumelo Swingle. Rev. Bras. Fruticult. 32(4):11801188.

21. SANTANA, D.L.; RENAL, M.A. 2000. Análise estatística na germinação. R. Bras. Fisiol. Veg. 12(edição especial):205-237.

22. SANTOS, C.Q.; GIRARDI, E.A.; VIEIRA, E.L.; LEDO, C.A.; SOARES FILHO, W.D. 2015. Tamanho ótimo de amostras de frutos e de sementes para determinação da poliembrionia em citros. Revista Brasileira Fruticultura 37(1):172-178.

23. SCHÄFER, G.; DORNELLES, A.L.C. 2000. Produção de mudas cítricas no Rio Grande do Sul - Diagnóstico da região produtora. Ciência Rural (Brasil). 30(4):587592.

24. SCHÄFER, G.; BASTIANEL, M.; DORNELLES, A.L. 2001. Porta-enxertos utilizados na citricultura. Ciência Rural. 31(4):723-733.
25. SCIVITTARO, W.B.; OLIVEIRA, R.P.; MORALES, C.F.; RADMANN, E.B. 2004. Adubação nitrogenada na formação de porta-enxertos de limoeiro 'Cravo' em tubetes. Rev. Bras. Fruticult. 26(1):131-135.

26. SIQUEIRA, D.L.; VASCONCELLOS, J.F.; DIAS, D.C.; PEREIRA, W.E. 2002. Germinação de sementes de porta-enxertos de citros após o armazenamento em ambiente refrigerado. Rev. Bras. Fruticult. 24(2):317322.

27. SOUSA, H.U.; RAMOS, J.D.; PASQUAL, M.; FERREIRA, E.A. 2002. Efeito do ácido giberélico sobre a germinação de sementes de porta-enxertos cítricos. Rev. Bras. Fruticult. 24(2):496-499.

28. SOUZA, P.V.; SOUZA, E.L.S.; OLIVEIRA, R.P.; BONINE, D.P. 2010. Indicações Técnicas para a Citricultura no Rio Grande do Sul. Ed. FEPAGRO (Porto Alegre). 126p.

29. TEIXEIRA, P.T.L.; SCHÄFER, G.; SOUZA, P.V.D.; TODESCHINI, A. 2009. A escarificação química e o desenvolvimento inicial de porta-enxertos cítricos. Rev. Bras. Fruticult. 31(30):865-871.

30. ZUCOLOTO, M.; GAMA DA COSTA, M.; CARVALHO, L.M.; DOS SANTOS, D.; SIQUEIRA, D.L. 2011. Estimativa da produção de sementes de portaenxertos cítricos por meio da massa de frutos. Ceres (Brasil). 58(1):126-128.

Recibido: Agosto 25 de 2015

Aceptado: Febrero 8 de 2016

\section{Cómo citar:}

Prato Sarmiento, A.I; Giuliani, J.C.; Dutra de Souza, P.V. 2016. Morfologia de frutos e sementes de porta-enxertos de citros cultivados em ambiente protegido. Rev. U.D.C.A Act. \& Div. Cient. 19(1): 17-24. 